\section{Sexing the Cranium from the Foramen Magnum Using Discriminant Analysis in a Brazilian Sample}

Thais Torralbo Lopez-Capp ${ }^{1}$, Christopher Rynn², Caroline Wilkinson ${ }^{3}$, Luiz Airton Saavedra de Paiva ${ }^{4}$, Edgard Michel-Crosato ${ }^{1}$, Maria Gabriela Haye Biazevic $^{1}$

\begin{abstract}
In the identification process, the foramen magnum has shown controversial results in sex estimation. The present study aimed to analyze the morphometric variables of the foramen magnum in Brazilian adult cranium for sex estimation. The sample was composed of 100 craniums (53 males and 47 females) from the documented collection of the Institute of Teaching and Research in Forensic Sciences. The protocol measurement was constituted of two linear measurements: maximum length of the foramen magnum and maximum breadth of the foramen magnum and two formulas to calculate the area, method one (M1) and method two (M2). Descriptive statistics showed statistically significant differences between sex $(p<0.05)$ for all variables. The univariate discriminant functions showed an accuracy between $56.0-62.0 \%$, and the multivariate analysis showed a percentage of accuracy between $60.0-65.0 \%$, the greatest accuracy was found combining the two linear measurements with M1(71.7\%), even after cross-validation (66\%). Receiver Operating Characteristic (ROC) curve analysis showed that M2 is the best parameter for estimating sex $(A \cup C=0.693)$. A reference table for Brazilians using the foramen magnum parameters was developed based on the results of the ROC curve analysis. In conclusion, the foramen magnum should be used with caution to estimate sex in forensic cases of fragmentary craniums, due to the limited accuracy.
\end{abstract}

\author{
'Department of Community \\ Dentistry, USP - Universidade de \\ São Paulo, São Paulo, SP, Brazil \\ ${ }^{2}$ Center of Anatomy and Human \\ Identification, University of \\ Dundee, Dundee, Scotland \\ ${ }^{3}$ Liverpool School of Art and \\ Design, Liverpool John Moores \\ University, Liverpool, England \\ ${ }^{4}$ EPCF - Instituto de Ensino e \\ Pesquisa em Ciências Forenses, \\ São Paulo, SP, Brazil
}

Correspondence: Maria Gabriela Haye Biazevic, Av. Professor lineu Prestes 2227, 05508-000 São Paulo, SP, Brasil. Tel.: +55-11-30917891.e-mail: biazevic@usp.br

Key Words: forensic sciences, forensic anthropology, foramen magnum, cranium, discriminant analysis, ROC curve, sex determination by skeleton.

\section{Introduction}

The basic precept of the science of forensic anthropology is to aid in the identification of human remains (1). The biological profile is the main result of a forensic anthropological examination. Several techniques are employed to achieve a common denominator, the construction of a biological profile that corroborates with a positive identification (1-3). Among the techniques described in the literature, the craniometry, which aims to use measurements of the human cranium in a systematic and universal way, enabling a comparative evaluation between studies carried out in different populations around the world, can be highlighted (4).

Craniometry aims to complement visually assessed traits, correcting the subjective aspect of the personal observations of the examiner. In short, craniometry allows the knowledge of the morphometric variabilities of human craniums, within the natural demands of scientific objectivity (5). The validation of quantitative methodology in the diverse populations around the world is of paramount importance for the global development of forensic anthropology, since the discriminant or regression formulas are sensitive to population variations, which may mean that methodologies developed and validated in a specific population may not be valid for application in another population (6-8). The use of quantitative methodologies is becoming more frequent due to the objectivity of the analysis and the increased methodological reproducibility $(6,7,9,10)$.

The first step in the design of the biological profile is the estimation of sex, as the sex of an individual is one of the main biological indicators of identity (11). Thus, craniometric analysis is considered a tool of great importance in all phases of anthropological examination. The applicability of craniometry for determining the sex of a cranium is only feasible in adults, with the development of secondary sexual characteristics (12). In the adult cranium, sexual dimorphism is inherent in the fragility of the female musculature, which results in a lesser development of the skeletal structures (13).

In view of the anatomical structures that make up the human cranium, the literature has observed that the base of the cranium is one of the structures with a greater chance of prevailing intact despite time and environmental factors (14-17). The diagnosis of sex in intact craniums does not pose a challenge to the examiner, but in cases of fragmented craniums, the estimation of this parameter becomes increasingly difficult (17). For this, the development of methodologies that are applicable to fragmented craniums is of paramount importance for the advancement of forensic anthropology. In this context, 
studies $(6,9,10)$ have shown that several anatomical regions can be used, and some of them are more accurate than others in sex estimation. Among these structures, the use of linear measurements and circumference area of the foramen magnum (15-23) are emphasized. The foramen magnum is an orifice in the occipital bone, located between the basilar part and the occipital scales, that carries the passage of the brainstem, spinal cord, accessory nerve and vertebral artery. It can be observed in the inferior view of the cranium (24).

In Brazil, few studies have been concerned with the characteristics of the national population. The miscegenation of the Brazilian population due to the intense migration process poses a challenge to forensic anthropologists, since morphometric parameters from other countries may not be valid for the national population (25). The present study aims to analyze the morphometric variables of the foramen magnum in Brazilian adult craniums for sex estimation, assessing its feasibility and reliability for the use in forensic situations.

\section{Material and Methods}

The total sample was comprised of 100 Brazilian adults' craniums (53 males and 47 females) with an average age was 57.03 years, with a minimum of 18 and a maximum of 104 (Table 1). The craniums are from the osteological documented collection of the Institute of Teaching and Research in Forensic Sciences (IEPCF). The craniums were exhumed from the Necrópolis Campo Santo cemetery, a public cemetery located in the city of Guarulhos, SP, Brazil. The sex was obtained from the cemetery records. The IEPCF collection is considered a contemporary collection once all the craniums coming out of the 20th century.

The adopted inclusion criteria were: absence of fractures in the foramen magnum area and skulls belonging to individuals older than 18 years. Exclusion criteria were trauma, bone pathologies and extensive fractures.

The protocol measurement of the present study was constituted of two linear measurement and two formulas to calculated the area of the circle based on past publications $(22,26)$. The 2 linear variables used in this study are included in Figure 1): maximum length of the foramen magnum (LFM): linear distance from basion (ba) to opisthion (o);

Table 1. Sample age: descriptive statistics

\begin{tabular}{lcccccc}
\hline Sex & $\mathrm{n}$ & Mean & SD & Median & Minimum & Maximum \\
Male $\delta$ & 53 & 54.15 & 18.95 & 56 & 18 & 97 \\
Female ++ & 47 & 60.28 & 18.89 & 61 & 20 & 104 \\
Total $\not \subset+$ & 100 & 57.03 & 19.07 & 57.5 & 18 & 104 \\
\hline
\end{tabular}

maximum breadth of the foramen magnum (BFM): distance between the lateral margins of the foramen magnum at the point of greatest lateral curvature.

The measures were performed directly on the craniums, using a Digital Caliper (Lee Tools, Houston, TX, USA) with an error margin of $0.01 \mathrm{~mm}$. All variables were recorded in $\mathrm{mm}$ with two decimal places. The interobserver and intraobserver agreement was performed by two observers in 20 skulls. The protocols were applied independently, at different times, and with a one-month interval between measurements; these skulls were not part of the final sample.

According to previous studies, the shape of the foramen magnum resembles a geometric circle $(22,26)$. As a result, the LFM and BFM can be used to calculate the area of the circle. In the present study, two formulas were used to calculate the area. The first formula (M1), which is based on the same variables measured in the present study, with LFM being the height ( $h$ ) and BFM being the width (W), was published by Teixeira (22): Area $=\pi \times((\mathrm{h} \times \mathrm{W}) / 4)^{2}$

The second method (M2) was described by Routal (26), utilizing the same measurements as described above: Area $=1 / 4 \times \pi \times W \times h$

The data were tabulated, and a descriptive analysis and independent $t$ test were performed to verify the differences between the groups (male and female). Univariate and multivariate discriminant analysis was used to study the sexual dimorphism of the sample. The discriminant function was created for each variable analyzed for each sex as follows: $\mathrm{P}=\mathrm{a}+\mathrm{b} 1^{*} \mathrm{x} 1+\mathrm{b} 2^{*} \mathrm{x} 2 \mathrm{a} 2+\ldots+b \mathrm{~m}^{*} \mathrm{xm}$, where $\mathrm{a}$ is $\mathrm{a}$

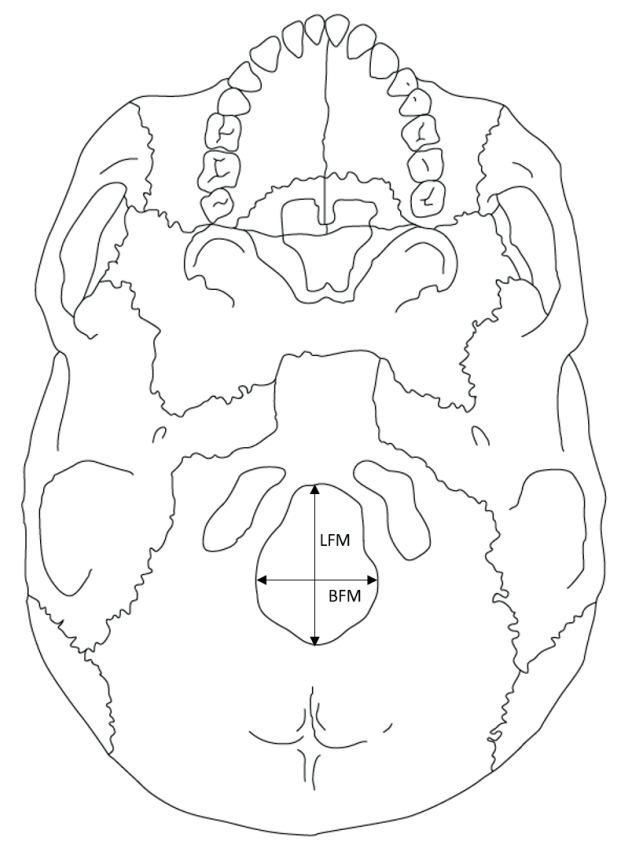

Figure 1. Foramen magnum measurements: vertical arrow LFM and horizontal arrow BFM. 
constant, $\mathrm{b} 1$ through $\mathrm{bm}$ are the discriminating coefficients, and $\mathrm{x} 1$ through $\mathrm{xm}$ are discriminating variables (17). To estimate the sex, the values of measurements must be included in the equation for male and female. The greatest product of $\mathrm{P}$ indicates the sex. The sectioning point for discriminant analysis were calculated using the mean of the female and male centroid group scores(17). Crossvalidation was applied to compensate for the percentage of misclassified observations. The receiver operating characteristic (ROC) curves were used to develop a reference table of the Brazilian population using foramen magnum parameters. The percentages of correct classifications in the table were $75 \%, 80 \%, 85 \%$, and $90 \%$, and the sectioning point was calculated using the mean of the medium values of the sexes (27). All tests were performed at a significance level of $5 \%$, the univariate and multivariate analyses were performed using the STATA 12.0 and the ROC curve analyses were carried out using MedCalc.

\section{Results}

The interobserver analysis demonstrated a moderate correlation ( $\mathrm{LFM}=0.59$ and $\mathrm{BFM}=0.55$ ). The intraobserver also showed moderate correlation for both variables but lower results ( $\mathrm{LFM}=0.41$ and $\mathrm{BFM}=0.40)(28)$.

The two methodologies of area calculation were compared, and statistically significant differences were found between the two formulas $(p<0.001)$. The results $\stackrel{\leftrightarrow}{\leftrightarrow}$ differences $(p<0.05)$ for all variables analyzed between sex. All means were greater for males compared to female means (Table 2).

The univariate discriminant functions showed an accuracy that varied between 56.0 and $62.0 \%$ (Table 3), and the multivariate analysis showed a percentage of accuracy between 60.0 and $65.0 \%$ (Table 3). The variable that demonstrated the greater percentage of accuracy was the M1 (62.0\%) followed by M2 (61.0\%). The association of LFM, BFM, and M1 showed the best result (65.0\%) in multivariate analysis.

The constants and variable coefficients necessary to construct the discriminant functions are shown in Table 3. For example, using the discriminant equations of the LFM and BFM, for an unknown adult cranium with the following measurements, $\mathrm{LFM}=33.22 \mathrm{~mm}$ and $\mathrm{BFM}=36.29$, the functions would be:

Male $=-114.84+\left(3.48^{*} 33.22\right)+\left(3.439^{*} 36.29\right)=125.56$

Female $=-104.3+\left(3.312^{*} 33.22\right)+\left(3.275^{*} 36.29\right)=$ 124.57

The products of the functions show that this unknown cranium is most likely to be male (64.2\%). The cross-validation analysis showed the same mean correct prediction values of the discriminant analysis for all univariate analysis and the associations of LFM + BFM $(62 \%)$ and BFM + M2 (60\%). For all other multivariate analyses, the cross-validation demonstrated reduced accuracy percentages.

The ROC curve analysis (Table 4) showed that M2 is the best parameter to estimate sex $(\mathrm{AUC}=0.693)$, followed by M1 (AUC $=0.691), B F M(A U C=0.633)$ and LFM $(A \cup C=0.627)$ (Fig. 2). A reference table was developed for the Brazilian population using the foramen magnum parameters based on the results of the ROC curve analysis (Table 5).

\section{Discussion}

The cranial base has been found to be the part of the cranium that is most likely to remain intact after the action of time and the environment $(14,16,17)$. The measurement of the foramen magnum to aid in the diagnosis of sex has been studied around the world, and the results have been controversial. Galdames (19), using the anteroposterior and transverse diameter of the foramen magnum in a Brazilian sample, concluded that these parameters should be used

Table 2. Descriptive statistics of the Brazilian sample measurements

\begin{tabular}{|c|c|c|c|c|c|c|c|c|c|c|}
\hline \multirow{2}{*}{$\begin{array}{l}\text { Variable* }^{*} \\
\text { LFM } \lesssim\end{array}$} & \multirow{2}{*}{$\frac{n}{53}$} & \multirow{2}{*}{$\begin{array}{l}\text { Mean } \\
32.36\end{array}$} & \multirow{2}{*}{$\frac{\mathrm{SD}}{3.26}$} & \multirow{2}{*}{$\begin{array}{c}\text { Median } \\
32.28\end{array}$} & \multirow{2}{*}{$\frac{\text { Minimum }}{26.24}$} & \multirow{2}{*}{$\frac{\text { Maximum }}{41.31}$} & \multirow{2}{*}{$\begin{array}{c}\text { Variance } \\
10.67\end{array}$} & \multicolumn{2}{|c|}{ 95\% CI } & \multirow{2}{*}{$\frac{p \text {-value }}{0.02}$} \\
\hline & & & & & & & & 31.46 & 33.26 & \\
\hline LFM $q$ & 47 & 30.79 & 3.3 & 30.62 & 25.30 & 39.53 & 10.89 & 29.82 & 31.76 & \\
\hline BFM $\widehat{\partial}$ & 53 & 33.7 & 3.62 & 34.05 & 25.12 & 41.75 & 13.13 & 32.70 & 34.70 & 0.02 \\
\hline $\mathrm{BFM}+$ & 47 & 32.09 & 3.04 & 32.41 & 25.23 & 37.99 & 9.26 & 31.20 & 32.99 & \\
\hline Method $1 \hat{\jmath}$ & 53 & 861.41 & 128.75 & 850.64 & 680.25 & 1256.64 & 16577.60 & 825.93 & 896.90 & $<0.001$ \\
\hline Method 1 ㅇ & 47 & 779.41 & 95.66 & 765.52 & 628.35 & 1027.80 & 9151.67 & 751.33 & 807.50 & \\
\hline Method $2 \hat{\jmath}$ & 53 & 856.32 & 129.2 & 841.51 & 671.39 & 1255.29 & 16692.80 & 820.71 & 891.93 & $<0.001$ \\
\hline Method 2 ㅇ & 47 & 774.15 & 96.03 & 754.65 & 623.81 & 1025.21 & 9222.34 & 745.95 & 802.35 & \\
\hline
\end{tabular}

LFM: maximum length of the foramen magnum; BFM: maximum breadth of the foramen magnum 
with caution due to the lower accuracy and should be implemented with qualitative analyses of the occipital bone. Gapert (17) concluded that in the analyzed sample, the area of the foramen magnum should be considered useful in determining the sex of the cranium.

In this study, all measurements analyzed demonstrated

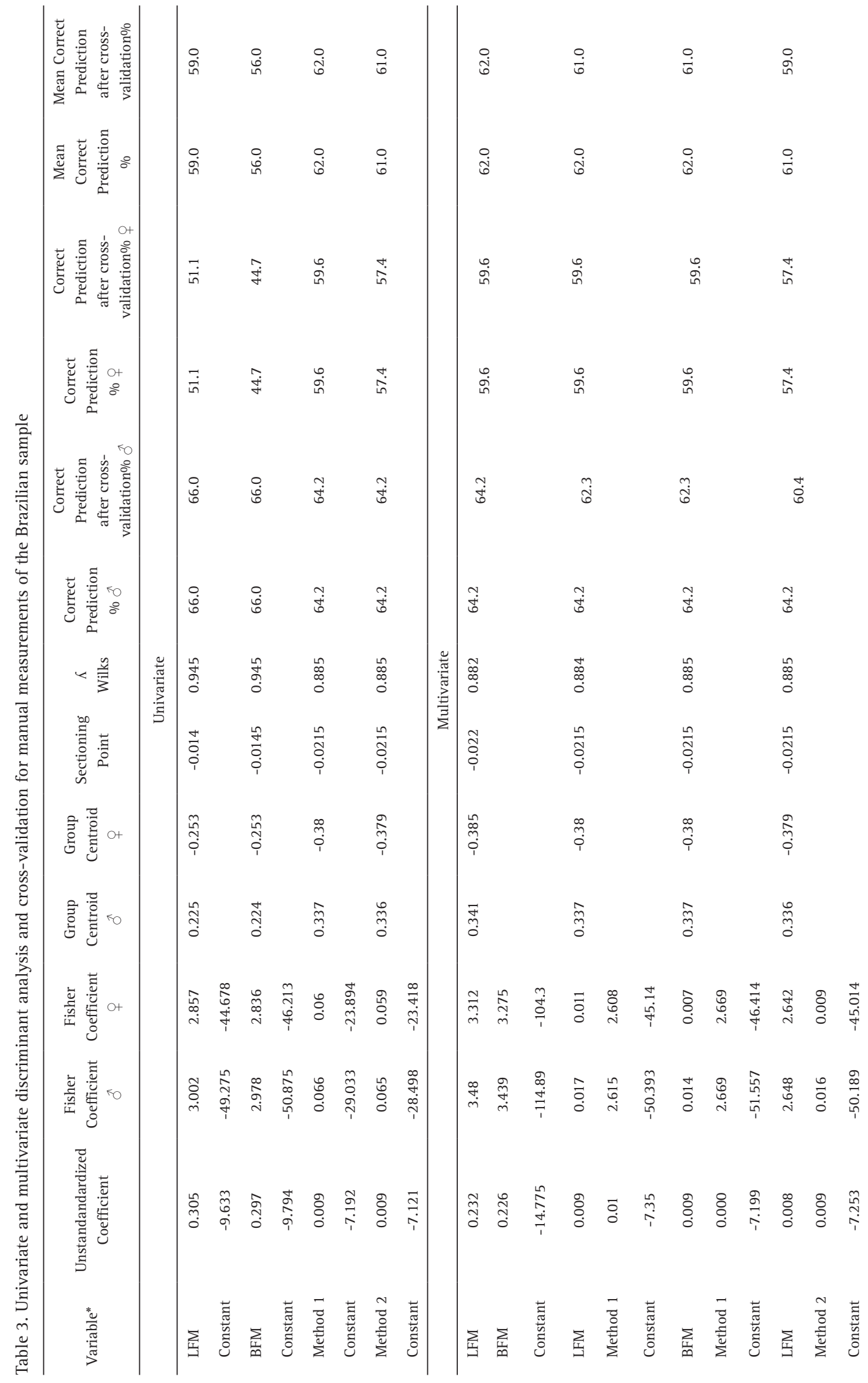


greater means in males compared to females and statistically significant differences between male and female craniums. These results are in agreement with those

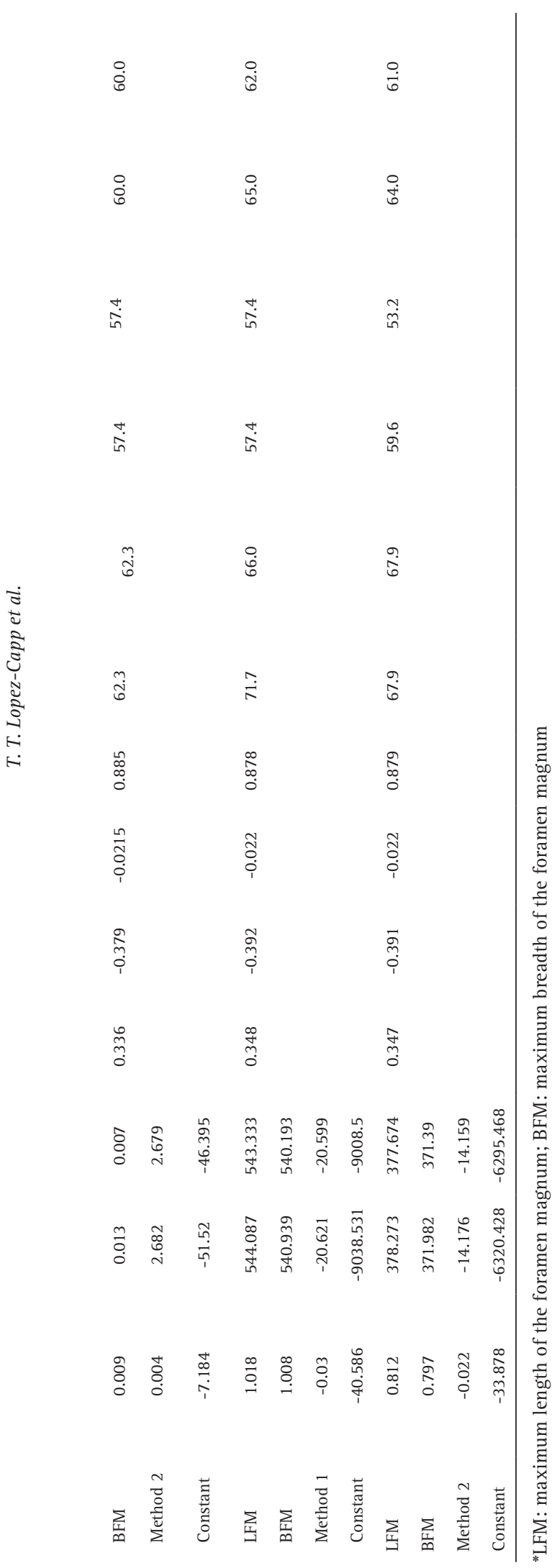

reported in recent studies (16-20).

The area calculated by Teixeira's formula (M1) showed the higher percentage of accuracy $(62.0 \% ; \lambda=0.885)$ in the univariate discriminant analysis followed by the $\mathrm{M} 2$ $(61.0 \% ; \lambda=0.885)$. The multivariate analysis demonstrated the best result for the association of the LFM, BFM, and $M 1$, with a percentage of accuracy of $65.0 \%(\lambda=0.878)$. The results of the present study revealed that the association of parameters does not increase the accuracy degree. Gapert (17) demonstrated a higher percentage of accuracy for the association of the maximum length and width (70.3\%) compared with the univariate analysis maximum width $(65.8 \%)$ and length (64.6\%). The percentage of accuracy found in the present study using univariate and multivariate analyses are in agreement with the recent literature $(15,16,18,21,23)$. It is important to highlight that the Wilks lambda $(\lambda)$ showed the low discriminating power of the variables analyzed in the present study, and it had improved as more variables increment the discriminant model, once the Wilks lambda scale ranges from 0 to 1 , where 0 means total discrimination, and 1 means no discrimination.

The ROC curve analysis showed similar results to those of the discriminant analysis. M2 showed a better probability of discriminating sex compared to M1. In a recent study on sex estimation using the foramen magnum parameters in craniums from the coastal Karnataka region of India, Babu et al. (18) described higher results than those reported in the present study that could be explained analyzing several factors: the differences in the population groups, the reproducibility of methodology, and a variance in statistical analysis. The foramen magnum length showed an area under the curve of 0.865 and 0.822 for the Teixeira Area. The foramen magnum breadth $(A \cup C=0.654)$ presented results like those of the present study.

Sex is a discrete dichotomous variable (male and female). Therefore, the probability of correctly estimating the sex at random is 50\%. The percentages achieved in the present using the foramen magnum to estimate sex were $14.6 \%$ higher than those yielded at random, which demonstrates the gracile of the methodology and the necessity to complement with other qualitative or quantitative parameters.

The reference table was developed to provide a new tool to optimize the process of construction of the biological profile. Due to the small sample analyzed in the present study, the discriminant functions and the reference table should be validated in a large sample of Brazilian individuals. Brazil is the fifth largest country in the world, having a wide range of climate and environmental variation. Additionally, it is the world's fifth most populous country, and the intense migratory process that makes up the Brazilian demography helped to construct a heterogeneous 
LFM

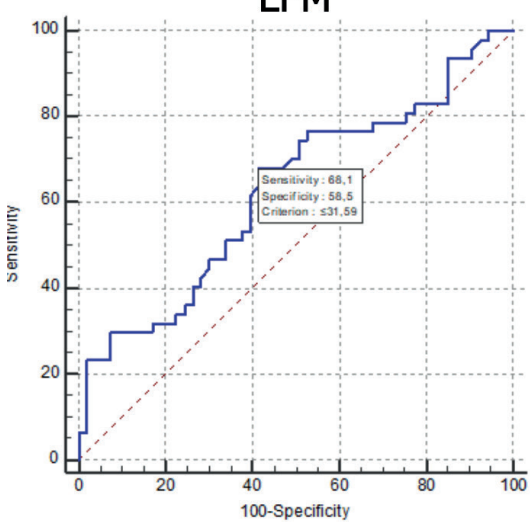

M1

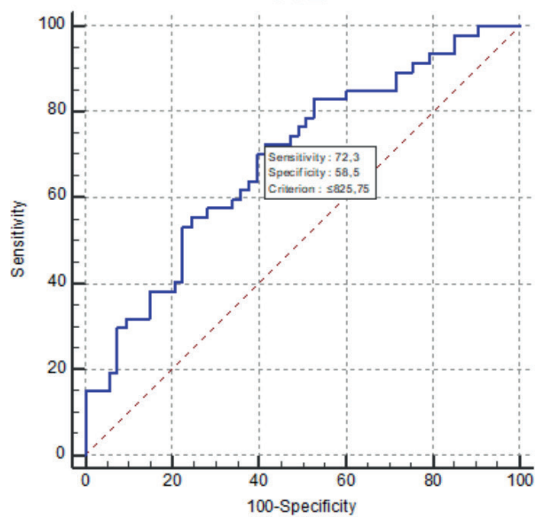

discriminant functions and the reference table developed in this study should be used in other nationalities with caution due to the craniometric variations. The validation of these tools is recommended before application in forensic cases. The present study was developed using craniums from a modern collection ( $20^{\text {th }}$ century), which is important to reduce the secular changes bias. The sex, age, and origin of the craniums that compound the sample of the present study are known, as these craniums are from a public cemetery that provided the obituary of these individuals to develop the records of this collection. The methodologies applied in forensic cases should be developed only in documented samples to reduce the methodological and social bias (17).

In conclusion, the foramen magnum should be used with caution to estimate sex in forensic cases of fragmentary craniums, due to the limited accuracy of this methodology. The application of these measurements should be complemented with other qualitative and/or quantitative parameters to

Figure 2. ROC curve graphs and sectioning points.

Table 4. ROC curve analysis for manual measurements of the Brazilian sample.

\begin{tabular}{|c|c|c|c|c|c|c|c|c|c|}
\hline Variable* & AUC & $p$ value & Lower Limit & Upper Limit & & Sectioning & & Male (\%) & Female $(\%)$ \\
\hline LFM & 0.627 & $<0.05$ & 0.524 & 0.721 & $q \leq$ & 31.59 & $\geq 0$ & 68.1 & 58.5 \\
\hline BFM & 0.633 & $<0.05$ & 0.531 & 0.727 & $q \leq$ & 33.85 & $\geq 0^{\lambda}$ & 74.5 & 50.9 \\
\hline Method 1 & 0.691 & $<0.05$ & 0.756 & 0.921 & $q \leq$ & 825.75 & $\geq 0$ & 72.3 & 58.5 \\
\hline Method 2 & 0.693 & $<0.05$ & 0.593 & 0.781 & $q \leq$ & 823.36 & $\geq 0$ & 72.3 & 58.5 \\
\hline
\end{tabular}

*LFM: maximum length of the foramen magnum; BFM: maximum breadth of the foramen magnum

Table 5. Reference table for manual measurements of the Brazilian population

\begin{tabular}{|c|c|c|c|c|c|c|c|c|c|}
\hline \multirow{2}{*}{ Variable } & \multicolumn{4}{|c|}{ Male } & \multirow{2}{*}{$\begin{array}{c}\text { Sectioning } \\
\text { Point }\end{array}$} & \multicolumn{4}{|c|}{ Female } \\
\hline & $95 \%$ & $90 \%$ & $80 \%$ & $70 \%$ & & $70 \%$ & $80 \%$ & $90 \%$ & $95 \%$ \\
\hline LFM & 35.83 & 35.31 & 34.17 & 32.28 & 31.57 & 30.13 & 29.2 & 28.26 & 27.56 \\
\hline BFM & 37.13 & 35.73 & 34.73 & 33.77 & 32.89 & 31.79 & 30.61 & 28.43 & 27.29 \\
\hline $\begin{array}{l}\text { Teixeira } \\
\text { Area }\end{array}$ & 968.17 & 901.26 & 857.89 & 822.45 & 820.41 & 787 & 745.3 & 710.63 & 686.97 \\
\hline Routal Area & 946.84 & 913.24 & 855.06 & 820.91 & 815.23 & 783.22 & 736.67 & 705.63 & 696.7 \\
\hline
\end{tabular}


increase the percentage of correct classifications. In cases of complete craniums, the application of methods with higher accuracy are recommended.

\section{Resumo}

No processo de identificação humana, a análise do forame magno apresenta resultados controversos para estimativa do sexo. 0 presente estudo teve como objetivo analisar as variáveis morfométricas do forame magno em crânios adultos brasileiros para estimação sexual. A amostra foi composta por 100 crânios (53 sexos masculino e 47 sexo feminino) pertencentes a coleção osteológica documentada do Instituto de Ensino e Pesquisa em Ciências Forenses. A medida do protocolo foi constituída por duas medidas lineares: comprimento máximo do forame magno e largura máxima do forame magno e duas fórmulas para calcular a área, método um (M1) e método dois (M2). As estatísticas descritivas evidenciaram diferenças estatisticamente significativas $(p<0,05)$ para todas as variáveis. As funções discriminantes univariadas apresentaram uma porcentagem de acerto entre $56,0-62,0 \%$ e a análise multivariada mostrou uma porcentagem de acerto entre $60,0-65,0 \%$. A análise da curva ROC apontou que M2 é o melhor parâmetro para estimar o sexo $(A \cup C=0,693)$. Uma tabela de referência para brasileiros que utilizam os parâmetros do forame magnum foi desenvolvida com base nos resultados da análise da curva ROC. Em conclusão, o foram e magnum deve ser usado com precaução para estimar o sexo em casos forenses de cranio fragmentado, devido à precisão limitada.

\section{$\therefore$ Acknowledgements \\ This investigation was funded by the State of São Paulo's Research Fund (FAPESP, process numbers 2014/13340-7, 2014/23727-6 and 2011/18577-7).

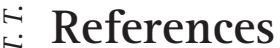

1. Cattaneo C. Forensic anthropology: developments of a classical discipline in the new millennium. Forensic Sci Int 2007;165:185-193.

2. Konigsberg LW, Algee-Hewitt BFB, Steadman DW. Estimation and evidence in forensic anthropology: Sex and race. Am J Phys Anthropol 2009;139:77-90.

3. Urbanová $\mathrm{P}$, Ross $A \mathrm{H}$, Jurda $\mathrm{M}$, Nogueira MI. Testing the reliability of software tools in sex and ancestry estimation in a multi-ancestral Brazilian sample. Leg Med 2014;16:264-273.

4. Howells WW. Cranial Variation in Man. A Study by Multivariate Analysis of Patterns of Differences Among Recent Human Populations. Cambridge, MA: Cambridge; $1973.259 \mathrm{p}$.

5. Buikstra JE, Ubelaker DH. Standards for data collection from human skeletal remains. Arkansas: Library of Congress Cataloging in Publication Data; 1994.

6. Franklin D, Cardini A, Flavel A, Kuliukas A. Estimation of sex from cranial measurements in a Western Australian population. Forensic Sci Int 2013;229:158 e1-e8.

7. Ogawa $Y$, Imaizumi K, Miyasaka S, Yoshino M. Discriminant functions for sex estimation of modern Japanese skulls. J Forensic Leg Med 2013;20:234-238.

8. Robinson MS, Bidmos MA. The skull and humerus in the determination of sex: Reliability of discriminant function equations. Forensic Science International 2009;186:e1-5.
9. Saini V, Srivastava R, Rai RK, Shamal SN, Singh TB, Tripathi SK. Sex Estimation from the Mastoid Process Among North Indians. J Forensic Sci 2012;57:434-439.

10. Vinay G, Mangala Gowri SR, Anbalagan J. Sex determination of human mandible using metrical parameters. J Clinical Diagn Res 2013;7:26712673.

11. Spradley MK, Jantz RL. Sex estimation in forensic anthropology: skull versus postcranial elements. J Forensic Sci 2011;56:289-296.

12. Gonzalez RA. Determination of sex from juvenile crania by means of discriminant function analysis. J Forensic Sci 2012;57:24-34.

13. Lang TF. The bone-muscle relationship in men and women. J Osteop $2011 ; 2011$

14. Giles $\mathrm{E}$, Elliot $\mathrm{O}$. Sex determination by discriminant function analysis of crania. Am J Phys Anthropol 1963;21:53-68.

15. Seifert Z, Friedl L, Chaumoitre K, Brůžek J. Applicability and limitations of sex assessment based on foramen magnum. Forensic Sci Int 2017;271:126.e1-e9.

16. Tambawala SS, Karjodkar FR, Sansare K, Prakash N, Dora AC. Sexual dimorphism of foramen magnum using Cone Beam Computed Tomography. J Forensic Leg Med 2016;44:29-34.

17. Gapert $R, B$ lack $S$, Last J. Sex determination from the foramen magnum: discriminant function analysis in an eighteenth and nineteenth century British sample. Int J Leg Med 2009;123:25-33.

18. Edwards K, Viner MD, Schweitzer W, Thali MJ. Sex determination from the foramen magnum. J Forensic Radiol Imag 2013;1:186-192.

19. Galdames ICS, Russo PR, Matamala DAZ, Smith RL. Sexual Dimorphism in the Foramen Magnum Dimensions. Int J Morphol 2009;27:21-23.

20. İlgüy D, İlgüy $M$, Ersan N, Dölekoğlu $S$, Fişekçioğlu E. Measurements of the foramen magnum and mandible in relation to sex using CBCT. J Forensic Sci 2014;59:601-665.

21. Madadin M, Menezes RG, Al Saif HS, Abu Alola H, Al Muhanna A, Gullenpet $\mathrm{AH}$, et al. Morphometric evaluation of the foramen magnum for sex determination: A study from Saudi Arabia. J Forensic Leg Med 2017;46:66-71.

22. Teixeira WR. Sex identification utilizing the size of the foramen magnum. Am J Forensic Med Pathol 1982;3:203-206.

23. Uthman AT, Al-Rawi NH, Al-Timimi JF. Evaluation of foramen magnum in gender determination using helical CT scanning. Dentomaxillofac Radiol 2012;41:197-202.

24. White T, Black M, Folkens P. Human Osteology-3rd. New York: Academic Press; 2011. $688 \mathrm{p}$.

25. Saloum de Neves Manta F, Pereira R, Vianna R, Rodolfo Beuttenmüller de Araújo $A$, Leite Góes Gitai $D$, Aparecida da Silva $D$, et al. Revisiting the genetic ancestry of brazilians using autosomal aim-indels. PLoS ONE 2013;8:e75145.

26. Routal RR, Pal GP, Bhagwat SS, Tamankar BP. Metrical studies with sexual dimorphism in foramen magnum of human crania. J Anat Soc India 1984;2:85-89.

27. Saini V, Srivastava $R$, Rai RK, Shamal SN, Singh TB, Tripathi SK. An osteometric study of northern indian populations for sexual dimorphism in craniofacial region. J Forensic Sci 2011;56:700-705.

28. Fleiss JL. Reliability of Measurement. The Design and Analysis of Clinical Experiments: John Wiley \& Sons, Inc; 1999. p. 1-32.

29. Pena SDJ, Di Pietro G, Fuchshuber-Moraes M, Genro JP, Hutz MH, Kehdy FdSG, et al. The genomic ancestry of individuals from different geographical regions of brazil is more uniform than expected. PLoS ONE 2011;6:e17063. 